\title{
Incorporating Guideline Adherence and Practice Implementation Issues into the Design of Decision Support for Beta-Blocker Titration for Heart Failure
}

\author{
Michael W. Smith ${ }^{1}$ Charnetta Brown ${ }^{2}$ Salim S. Virani ${ }^{2,3}$ Charlene R. Weir ${ }^{4,5}$ Laura A. Petersen ${ }^{2,6}$ \\ Natalie Kelly ${ }^{4}$ Julia Akeroyd ${ }^{2}$ Jennifer H. Garvin ${ }^{4,5,7,8}$
}

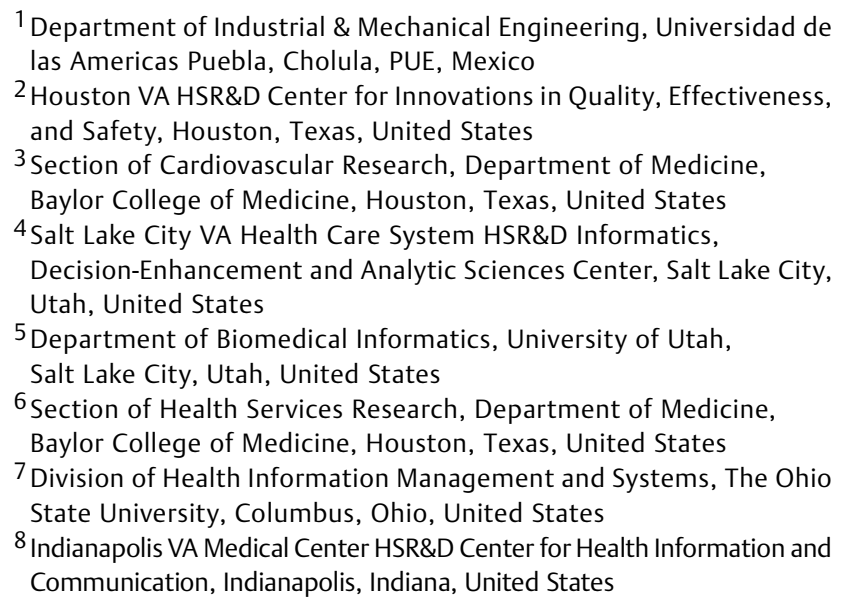

Address for correspondence Michael W. Smith, PhD, Department of Industrial \& Mechanical Engineering, Universidad De Las Americas Puebla, Ex hacienda Sta. Catarina Martir, San Andres Cholula, Puebla 72810, Mexico (e-mail: Michael.Smith@udlap.mx).

Appl Clin Inform 2018;9:478-489.

\begin{abstract}
Keywords

- clinical decision support

- heart failure

- computer systems development

- primary health care

- adrenergic $\beta$-antagonists

Background The recognition of and response to undertreatment of heart failure (HF) patients can be complicated. A clinical reminder can facilitate use of guideline-concordant $\beta$-blocker titration for HF patients with depressed ejection fraction. However, the design must consider the cognitive demands on the providers and the context of the work.

Objective This study's purpose is to develop requirements for a clinical decision support tool (a clinical reminder) by analyzing the cognitive demands of the task along with the factors in the Cabana framework of physician adherence to guidelines, the health information technology (HIT) sociotechnical framework, and the Promoting Action on Research Implementation in Health Services (PARIHS) framework of health services implementation. It utilizes a tool that extracts information from medical records (including ejection fraction in free text reports) to identify qualifying patients at risk of undertreatment.

Methods We conducted interviews with 17 primary care providers, 5 PharmDs, and 5 Registered Nurses across three Veterans Health Administration outpatient clinics. The interviews were based on cognitive task analysis (CTA) methods and enhanced through the inclusion of the Cabana, HIT sociotechnical, and PARIHS frameworks. The analysis of the interview data led to the development of requirements and a prototype design for a clinical reminder. We conducted a small pilot usability assessment of the clinical reminder using realistic clinical scenarios.
\end{abstract}

received

December 18, 2017

accepted after revision

May 12, 2018
Copyright @ 2018 Schattauer
DOI https://doi.org/ $10.1055 / \mathrm{s}-0038-1660849$. ISSN 1869-0327. 
Results We identified organizational challenges (such as time pressures and underuse of pharmacists), knowledge issues regarding the guideline, and information needs regarding patient history and treatment status. We based the design of the clinical reminder on how to best address these challenges. The usability assessment indicated the tool could help the decision and titration processes.

Conclusion Through the use of CTA methods enhanced with adherence, sociotechnical, and implementation frameworks, we designed a decision support tool that considers important challenges in the decision and execution of $\beta$-blocker titration for qualifying $\mathrm{HF}$ patients at risk of undertreatment.

\section{Background and Significance}

Heart failure (HF) is an increasingly prevalent problem. ${ }^{1}$ One of the treatments that has shown to improve clinical outcomes in HF patients with depressed ejection fraction is the use of $\beta$-blocker at optimal doses; their use is currently a class $1 \mathrm{~A}$ recommendation per the American College of Cardiology and American Heart Association guidelines. ${ }^{2,3}$ The guidelines also recommend that "physicians should make every effort to achieve the target doses of the betablockers shown to be effective in major clinical trials." ${ }^{4-7}$ Patients with HF and depressed ejection fraction have better symptom management and survival when treated in accordance with the guidelines. ${ }^{8}$ Beta-blocker use at optimal doses has also been associated with a reduction in hospital readmissions. ${ }^{9-13}$

Unfortunately, a large portion of patients with HF and depressed ejection fraction are not receiving guidelinerecommended medication treatment ${ }^{14}$-incorrect $\beta$-blocker drugs are used, or the dosage is too low, or there is no use of $\beta$-blockers. ${ }^{7,15,16}$ A recent global survey found that although $87 \%$ of HF patients with reduced ejection fraction were on $\beta$-blockers, only $15 \%$ were at the target dose. ${ }^{17}$

The decision for determining the best target dose of $\beta$-blocker is complex. However, prior work has explored the use of clinical decision support systems (CDSS) in supporting management of $\mathrm{HF}$ by primary/general practitioners. $^{18-20}$ Leslie et $\mathrm{al}^{18}$ identified challenges to $\mathrm{HF}$ treatment including inadequate support for uptitration of $\beta$-blockers, and how nonmedical needs of patients can complicate treatment decisions. Toth-Pal et al $^{19}$ found that CDSS can impact medication decisions, but also that the time involved in using a CDSS is a concern for providers. Smeets et $\mathrm{al}^{21}$ report that the treatment of HF by primary care providers (PCPs) is hampered by a lack of access to specialized knowledge; one suggestion is to use CDSS to integrate evidence-based guidelines into clinical practice.

The purpose of this article is to report on the requirements development and design of a CDSS tool that will inform and motivate primary care clinicians in making the decision about $\beta$-blocker use for patients at risk for undertreatment. We focus on primary care because of the greater number of and access to PCPs compared with cardiologists, and the greater likelihood that a patient who is not seeing a cardiologist may be receiving suboptimal treatment. The tool we present here is based on a software developed to read ejection fraction from free text reports in electronic health records (EHRs) ${ }^{22}$ to identify $\mathrm{HF}$ patients with depressed ejection fraction who might qualify for high doses of $\beta$-blockers but are not receiving them. ${ }^{23}$ It is different than prior CDSS tools focused on $\mathrm{HF}^{18,19}$ in that (1) it is focused specifically on $\beta$-blocker titration for reduced ejection fraction patients; and (2) it identifies if a given patient is at risk and pushes a notification to the provider at an appropriate time, rather than requiring the provider to recognize a problem and seek out the tool.

Simply giving PCPs information on potentially undertreated HF patients may not lead to better use of $\beta$-blockers. ${ }^{24}$ There are challenges related to both the task of making medication decisions for HF patients, and to the context in which the decision is made. In HF patients with depressed ejection fraction, titration to optimal doses, and maintenance at those doses, can be a complex process. Fluid retention needs to be carefully monitored. Beta-blocker use can affect blood pressure and heart rate, and requires careful management in patients being treated for those conditions as well. ${ }^{25}$ These demands occur in the context of time constraints on primary care with many clinical reminders for multiple conditions, making it challenging to spend time managing chronic diseases. ${ }^{26,27}$ Additionally, decisions about HF management can be influenced by uncertainty about clinical practice, personal experience with HF management, and the availability of resources. ${ }^{28}$

These factors are important in adoption and observance of guidelines. ${ }^{29}$ Understanding these factors, and considering them in the design of the CDSS, is critical for developing a tool that both meets the needs of the end user, and is designed with an understanding of the context in which it will be used. Fortunately, there are existing frameworks and design research methods that can help with the development aspects.

The Promoting Action on Research Implementation in Health Services (PARIHS) ${ }^{30}$ implementation framework emphasizes characteristics of the clinical contents and the organizational context in implementation. It includes three important areas-evidence, context, and facilitation-all of which should be used to translate evidence-based guidelines into actual clinical practice. 
Part of the organizational context and facilitation of clinical work depends on the health information technology (HIT) and its integration with the organization. This is included in the HIT sociotechnical framework, ${ }^{31}$ based on the Systems Engineering Initiative for Patient Safety model. ${ }^{32,33}$ This framework lists several areas that are important to consider regarding fit of HIT tools in the sociotechnical context of their operation, including clinical content, human-computer interface, and workflow and communication.

The Cabana framework ${ }^{34}$ looks at provider-related dimensions to explain barriers related to adherence to clinical practice guidelines. It looks at gaps in the areas of knowledge, attitude, and practice required for following the practices recommended by the guideline.

These frameworks have been used for evaluation and implementation of solutions, and the identification of barriers and facilitators; ${ }^{35}$ however, their use as part of requirements development is much less evident. One exception is Sheehan et al's ${ }^{36}$ use of sociotechnical analysis to inform the design of a CDSS for pediatric head trauma.

The three frameworks fit together to help identify how the provider must execute the practice recommended by the guideline in the sociotechnical context of the organization. Cabana focuses on providers' adherence to guidelines, especially in terms of knowledge and attitude. ${ }^{34}$ PARIHS focuses on the content and context of the work involved in following the new practice. ${ }^{30}$ The HIT sociotechnical model focuses on how the overall HIT-enabled health care system supports safe and effective care delivery. ${ }^{31}$ Collectively, these three frameworks provide an approach that incorporates the individual provider, the work context, and the overall system.

To help translate these demands into functions performed by the provider, and therefore design requirements for the CDSS, we used the cognitive tasks analysis (CTA) methodology. ${ }^{37}$ This is a family of methods for studying the patterns of cognitive work in real-world, complex contexts, to identify challenges for practitioners and opportunities to provide better support. Such analysis is important for generating design requirements that will address the challenges of the practitioners-in this case, the challenges faced by providers in implementing the $\beta$-blocker guidelines related to $\beta$-blocker use and performing dose titration when appropriate for qualifying HF patients. Developing systems by focusing on meeting the cognitive needs of the users is recommended to facilitate adoption. ${ }^{38,39}$ This is especially important for CDSS. ${ }^{40}$

CTA includes study of both the cognitive work of the practitioner and the essential characteristics of the work domain. ${ }^{41}$ The use of the frameworks to guide and enhance the CTA is a way to incorporate into the CTA some important theoretical insights about processes and challenges in the domain of health care. The frameworks provide an understanding of general implementation and adoption issues in the complex sociotechnical context of HIT-enabled health care systems. The CTA-based requirements elicitation process incorporates these issues along with the specific cognitive challenges of HF treatment and $\beta$-blocker titration, pointing out opportunities (requirements) for supporting the cognitive work of the providers (See - Fig. 1).

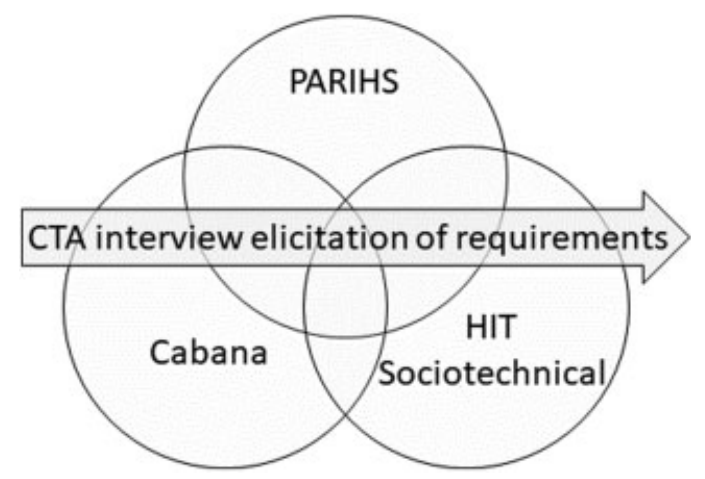

Fig. 1 Cognitive task analysis (CTA)-based requirements elicitation process informed by theoretic frameworks.

\section{Objective}

The purpose of this study is to develop (1) requirements and (2) a prototype design for a clinical decision support tool. This tool gives PCPs targeted information on HF patients with depressed ejection fraction who quality for guideline-recommended $\beta$-blocker treatment but are not receiving it. The requirements are generated via qualitative data collection and analysis based on CTA methods ${ }^{42}$ enhanced through the integration of the PARIHS, HIT sociotechnical, and Cabana frameworks. ${ }^{43}$ The goal is to address issues of adoption and implementation as early as possible in the design process, instead of trying to address them only after a tool has been developed. A secondary objective of the study is to conduct an initial assessment of the design via a pilot usability evaluation.

\section{Cognitive Task Analysis}

We conducted CTA interviews with providers, and analyzed the results, to inform the design requirements (described in this section). Afterwards, these results were used to help develop a prototype Clinical Reminder (the "Clinical Reminder Prototype" section). This was reviewed by a few key informants, and refined based on their feedback. The revised prototype was then usability tested with a few PCPs (the "Usability Review" section).

\section{Cognitive Task Analysis Methods}

\section{Setting and Participants}

The setting was the Veterans Health Administration(VHA). The interviews were conducted at three outpatient clinics from the same regional network. One was in a large city, one in a medium-sized city, and one in a rural area. All the clinics had implemented the VHA's medical home model for primary care, called Patient Aligned Care Team (PACT). ${ }^{44}$ Our analysis of the larger two of these sites found that only $62 \%$ of HF patients were receiving a $\beta$-blocker, which is similar to the findings of an earlier nationwide Veterans Affairs (VA) study. ${ }^{45}$

We recruited three types of PACT members: PCPs, clinical Pharmacists (PharmDs), and Registered Nurses (RNs). By interviewing PharmDs and RNs, who play important roles 
in collecting information about and providing treatment for HF patients, we were able to more fully understand the context in which PCPs are doing clinical evaluations and assessing medication options. We used convenience sampling based upon participant availability during the days of our visits to each facility. Institutional review board approval was obtained for this study.

\section{Data Collection}

We developed specific interview guides for each provide role (PCP, PharmD, RN). The interview guides were pilot tested with three providers (one PCP, one PharmD, and one RN) at another VHA site. The guides included questions on the provider's role in HF management, and how the provider learned of information about specific patients' care needs. The guides for the PCP and PharmD included questions about their knowledge of the guideline, attitudes toward such guidelines, experience with systolic HF management, and familiarity with $\beta$-blocker titration. Questions about organizational environment and EHR issues were also included. Thus, the guides incorporated elements from the Cabana, PARIHS, and sociotechnical frameworks.

To ensure responses were grounded in actual experience of work-as-performed, we also asked participants to walk us through their management of a recent HF case (as per the critical decision method ${ }^{46}$ ), with emphasis on what decisions they needed to make and what factors they needed to consider. The key relevant interview questions are presented in - Table 1.

The interviews were semistructured, and conducted in person by two team members (M.S. and C.B.) who took notes. They took place onsite in vacant rooms or the participant's private office. They were audio-recorded and transcribed. Each interview lasted between 30 and 60 minutes.

The interviews were designed to identify the factors related to the decision about whether or not to titrate a patient to target doses of $\beta$-blockers. Note that during the interview phase of the project, the decision to develop a clinical reminder had not been reached.

\section{Data Analysis}

We analyzed the data using the framework approach. ${ }^{47,48}$ Two coders (M.S. and C.B.) independently reviewed the data. During the initial informal pass, the coders followed an inductive approach based on the literature on health care teamwork $^{49}$ and PACTs, ${ }^{50,51}$ and also looked for emergent themes. After discussions among the interdisciplinary team, the coding approach was refined, following a deductive approach based on the Cabana, PARIHS, and HIT sociotechnical frameworks. With this approach, the PARIHS and HIT sociotechnical frameworks helped to identify organizational factors (reflecting the context of work), as well as patient and clinical factors (reflecting the content of work). The Cabana framework helped to identify the factors associated with the providers' knowledge, skills, and attitudes.

The two coders used Atlas.ti to code the data. A subset of transcripts was coded by both coders independently, to establish intercoder reliability. Afterwards, the remaining transcripts were coded only by one or the other coder. In an iterative process, the coding results were jointly reviewed and interpreted. As an additional cross-check, each coder evaluated the other coder's results by comparing them to their own interview notes and postinterview assessments (which served as an independent summary for comparison).

The results were reviewed by our interdisciplinary research team (which included specialists in cardiology, psychology, cognitive systems engineering, and medical informatics). The team identified patterns in the results regarding: cognitive work of $\beta$-blocker titration decisions; knowledge and attitudes; work context; and system barriers and facilitators. These patterns helped frame design requirements.

\section{Cognitive Task Analysis Interview Results}

For the CTA interviews there were a total of 17 participants: 7 PCPs (2 physicians, 5 nurse practitioners), 5 PharmDs, and 5 RNs. Note that this is a typical sample size for naturalistic CTA studies. ${ }^{52}$ The sample of PCPs has only two physicians, but the ratio of physicians to nurse practitioners is reflective of the staffing in primary care at these sites. Overall average number of years in practice was 18 (standard deviation, 9.6); PCPs had 17, PharmDs had 6, and RNs had 26 years on average. - Table 2 summarizes the main issues mentioned in the CTA interviews.

\section{Organizational and Patient Factors}

Participants mentioned various organizational factors that affect titration and other ways of managing systolic HF. Most PCPs did not refer their patients to pharmacists. One pharmacist indicated that most PCPs see pharmacists as useful for chronic disease management, but that $\beta$-blocker titration was not a common reason for referral. Some PCPs were of the opinion that most HF patients were working with cardiologists, meaning that the PCP would leave cardiac issues alone. Also mentioned was how patients who use both private specialists along with VA care presented challenges regarding accessing and sharing medical record information.

There was uncertainty and inconsistency about which of the three approved drugs (metoprolol succinate, carvedilol, and bisoprolol) was available in the providers' VA sites, and which were available only as a second-line treatment or not at all.

Resource limits and time pressures were often mentioned. An RN noted how PACT in theory should utilize RNs for chronic care management, but in practice the RNs were too busy with other responsibilities and did not have time for preventative and chronic care management. One PCP mentioned that the time burden of seeing a patient every 2 weeks for titration was a difficulty. The burden for patients, especially those living far away from the clinic, or with transportation challenges, was also raised.

Other patient factors brought up included the impact of $\beta$-blockers on energy levels and functional capacities, as well as the potential instability of patients (in terms of volume status and other aspects of compensatory capacity) and how this was affected by dietary issues. These make $\beta$-blocker titration more complicated. 
Table 1 Representative key interview questions

\begin{tabular}{|c|c|}
\hline Role & Question \\
\hline RN & How about for management of patients with chronic conditions, like CHF? What is your role? \\
\hline PharmD & $\begin{array}{l}\text { In terms of managing medications for outpatients with congestive heart failure, what is your role? } \\
\text { - What is your scope of practice relative to that area? Which orders, if any, need to be cosigned by the PCP? } \\
\text { - In terms of the management of a patient with CHF, how do you interact with the PACT teamlet? }\end{array}$ \\
\hline PCP & $\begin{array}{l}\text { Have you ever had a patient with systolic CHF who was hospitalized and later discharged for exacerbation of systolic } \\
\text { CHF? Yes? So, do you recall... } \\
\text { - No? Well, think about any cases you may have had regarding a patient with a chronic conditions (such as CHF) being } \\
\text { discharged. } \\
\text { - How did you/would you learn about this patient being discharged? } \\
\text { - Let's say you do have a patient who was recently discharged after being hospitalized for exacerbation of systolic } \\
\text { CHF... What was/would be the process for follow-up? } \\
\text { - What challenges are there that make it harder to accomplish this postdischarge follow-up? }\end{array}$ \\
\hline $\begin{array}{l}\text { PCP, } \\
\text { PharmD }\end{array}$ & $\begin{array}{l}\text { In terms of the management of the patient's systolic CHF, what were you/would you be looking at or thinking about? } \\
\text { - What medications would you look at? } \\
\text { o Are } \beta \text {-blockers a medication type that you have used with systolic CHF patients? } \\
\text { o Which } \beta \text {-blockers have you used for systolic CHF patients? } \\
\text { - How to you determine the dosage for the patient? } \\
\text { o Do you keep them on one dose, or do you titrate the dose at each visit? Why? When do you titrate (only if BP is } \\
\text { elevated, or as long as BP is not too low)? } \\
\text { - What challenges make it difficult for you to achieve use of } \beta \text {-blockers with your patients? }\end{array}$ \\
\hline PCP & In general, do you find guidelines helpful? Do you have any concerns about the role of guidelines in primary care? \\
\hline $\begin{array}{l}\text { PCP, } \\
\text { PharmD }\end{array}$ & $\begin{array}{l}\text { I'd like to ask you about guidelines for CHF management. Are you familiar with CHF management guidelines? Has } \\
\text { someone told you about them? } \\
\text { - Can I ask you a couple of things about the guidelines? It is just to see what info we might want to repeat in any } \\
\text { reminder notification, or what would be redundant. } \\
\text { o For the } \beta \text {-blockers you have used for systolic CHF (NAME OF } \beta \text {-BLOCKER), do you know the target doses recommended } \\
\text { in the guideline? } \\
\text { o Do you know the purpose of using } \beta \text {-blockers in systolic CHF patients? }\end{array}$ \\
\hline $\begin{array}{l}\text { PCP, } \\
\text { PharmD }\end{array}$ & $\begin{array}{l}\text { Do you have any concerns about the CHF guidelines and how they relate to your systolic HF patients? } \\
\text { - Do you have any concerns about prescribing } \beta \text {-blockers to systolic CHF patients? }\end{array}$ \\
\hline PharmD & Can you walk me through the titration process? Who would be involved? How would information be coordinated? \\
\hline PCP & $\begin{array}{l}\text { Is titrating } \beta \text {-blockers to the guideline recommended doses something you feel comfortable with doing for a systolic } \\
\text { CHF patient, or is that something you would have a pharmacist or cardiologist or other person do? } \\
\text { - Can you tell me what is it about [pharmacists, cardiologist] that makes them a better choice for handling that? }\end{array}$ \\
\hline $\begin{array}{l}\text { PCP, } \\
\text { PharmD }\end{array}$ & $\begin{array}{l}\text { Are there any factors or issues which prevent you from titrating to the guideline recommended doses? } \\
\text { - Are there tools you use to help with titration? }\end{array}$ \\
\hline $\mathrm{RN}$ & $\begin{array}{l}\text { We are considering situations where a patient with a chronic condition gets discharged from the hospital, but } \\
\text { treatment for that chronic condition is not sufficiently reviewed and updated. } \\
\text { - What factors would contribute to those sorts of problems in an outpatient clinic? Bigger panel, less staff, more } \\
\text { complex patients... } \\
\text { - Think about a time or place where the working conditions were more difficult. Under those conditions, how did you } \\
\text { monitor and keep track of things? } \\
\text { - Under those conditions, how might you have responded to that type of notification-about a discharged patient not } \\
\text { getting guideline recommended care for his chronic condition? }\end{array}$ \\
\hline PCP & $\begin{array}{l}\text { What determines if a patient gets CHF treatment primarily from a CHF clinic, a cardiology specialist, or by you and } \\
\text { your PACT? }\end{array}$ \\
\hline $\begin{array}{l}\text { PCP, } \\
\text { PharmD, } \\
\text { RN }\end{array}$ & $\begin{array}{l}\text { Imagine you (or someone in your PACT) gets a notification that says that our software has detected that one of your } \\
\text { patients has recently been discharged from the hospital (admitted for CHF exacerbation)-and that it looks like they } \\
\text { may qualify for being titrated up to guideline recommended levels of } \beta \text {-blocker. } \\
\text { - Tell me what that message means to you. } \\
\text { - What would be done? What might be different as compared with the process you described before? } \\
\text { - What would you look at to evaluate the patient for treatment with } \beta \text {-blockers? } \\
\text { - What information would you want from the notification? }\end{array}$ \\
\hline $\begin{array}{l}\text { PCP, } \\
\text { PharmD }\end{array}$ & $\begin{array}{l}\text { You mentioned some of the factors that make it harder to manage postdischarge follow-up, and to get patients on } \\
\beta \text {-blockers. When those factors are in play-when there is more workload, when communication and engagement } \\
\text { with the patient is harder, what do you do different in terms of postdischarge follow-up for CHF? In terms of } \\
\text { medication management? How and when do you look at: discharged patients? Patients being titrated? Patients with } \\
\text { CHF? How are other PACT members involved? } \\
\text { - Under those conditions, how would you respond to that type of notification-the one about a CHF patient who } \\
\text { wasn't getting guideline recommended } \beta \text {-blocker treatment? }\end{array}$ \\
\hline
\end{tabular}

Abbreviations: CHF, congestive heart failure; PACT, Patient Aligned Care Team; PCP, primary care provider; RN, Registered Nurse. 
Guideline and Titration Attitudes and Knowledge

Some PCPs expressed some hesitancy at $\beta$-blocker titration. One had developed a risk-averse strategy of referring to specialists when possible. Another had a specific dose limit beyond which cardiology would be invited to take over. Similarly, some PCPs reported that they would refer to pharmacists or cardiologists for complex patients.

All of the PCPs knew of the guideline, but many showed an incomplete understanding of the rationale for the guideline, as well as the approved drugs and target doses. Most had used one or two of the approved medications. Some were unclear on which version of metoprolol was approved, thinking it was tartrate instead of succinate.

Most expressed a positive opinion of clinical guidelines overall in helping to provide quality care. A few also shared concerns that emphasis on this clinical guideline could contribute to aggressive titration without due consideration of side effects.

\section{Clinical Data}

Collectively, a large number of clinical factors were identified as important to consider when assessing clinical need for and potential tolerance of high $\beta$-blocker dosing. These included:

- Age.

- Ejection fraction.

- Other cardiac data (blood pressure, heart rate).

- Co-morbidities (diabetes, renal problems, chronic obstructive pulmonary disease [COPD], asthma).

- HF symptoms, functional status.

- Patient stability (indicated by trends in weight, blood pressure, heart rate).

This last point reiterates how knowing the date of the diagnosis or measurement was important to how it should be interpreted. It was also noted that accessing ejection fraction, and getting data from various time points to assess stability, are cumbersome tasks to do in the EHR ( $>$ Table 2).

\section{Clinical Reminder Prototype}

\section{Design Process}

Working as a team, we used the analysis of the interviews and the patterns we found to identify the needs of the providers during consideration of $\beta$-blocker titration for systolic HF patients. These information, workflow, and coordination needs were used to generate requirements for the functioning of the notification and decision support tool. Based on the requirements, we determined that the tools would best be implemented as a VISTA clinical reminder. These are large dialogue windows that appear when a provider is starting a patient visit note (see -Fig. 2: example of typical clinical reminder), usually to remind providers to complete certain screening tasks that are due for that patient. ${ }^{53}$

The team generated various design concepts for clinical reminders to meet the requirements, eventually narrowing it down to a set of concepts that were used to create an initial nonfunctional prototype. This prototype was reviewed by team members and refined accordingly.

\section{Design Results}

Key informants from the three sites gave us feedback on the initial design (described in the next section). They identified some issues with the wording at the top, and the formatting of dates. Based on this feedback we made a revised prototype, show in -Fig. 3. Our design incorporates several features to meet the needs identified through the framework-enhanced CTA interview. These are identified by the numbered callouts in -Fig. 3.

1. The evidence for the guideline is briefly presented at the top.

2. The latest ejection fraction results are provided, including the date and source of the measurement.

3. The patient's current $\beta$-blocker medication and dose, if any, are provided.

4. The three approved medications and their target doses are listed.

5. The provider can make a quick decision if their patient does not qualify. In this case, only minimal interaction is needed to satisfy the clinical reminder. This means that if providers do not need to consider $\beta$-blocker titration, the time imposition is minimized. Further interaction is only for cases where assessment for titration is warranted.

6. Data from the last few measures of weight, blood pressure, and heart rate are presented to help the provider assess stability.

Table 2 Main issues from CTA interview results

\begin{tabular}{|l|l|}
\hline $\begin{array}{l}\text { Organizational factors } \\
\text { (reflecting PARIHS and HIT } \\
\text { sociotechnical context of work) }\end{array}$ & $\begin{array}{l}\text { - Underutilization of pharmacists } \\
\text { - Concern about interfering with plans of cardiologist or private specialist } \\
\text { - Uncertainty and inconsistency about approved } \beta \text {-blockers on formulary } \\
\text { - Shortage of time and staff for chronic care management and titration }\end{array}$ \\
\hline $\begin{array}{l}\text { Patient factors and clinical data } \\
\text { (reflecting PARIHS and HIT } \\
\text { sociotechnical content of work) }\end{array}$ & $\begin{array}{l}\text { - Impact of } \beta \text {-blockers on patient functional capacity } \\
\text { - Lack of patient stability } \\
\text { - Important clinical data to consider in decision } \\
\text { (includes age, comorbidities, cardiac functioning) }\end{array}$ \\
\hline $\begin{array}{l}\text { Provider knowledge, skills, attitudes } \\
\text { (reflecting Cabana framework) }\end{array}$ & $\begin{array}{l}\text { - Risk or difficulty threshold of when to refer to specialist } \\
\text { - Partial understanding of rationale for guideline } \\
\text { - Positive opinion about clinical guidelines in general }\end{array}$ \\
\hline
\end{tabular}

Abbreviations: CTA, cognitive task analysis; HIT, health information technology; PARIHS, Promoting Action on Research Implementation in Health Services. 


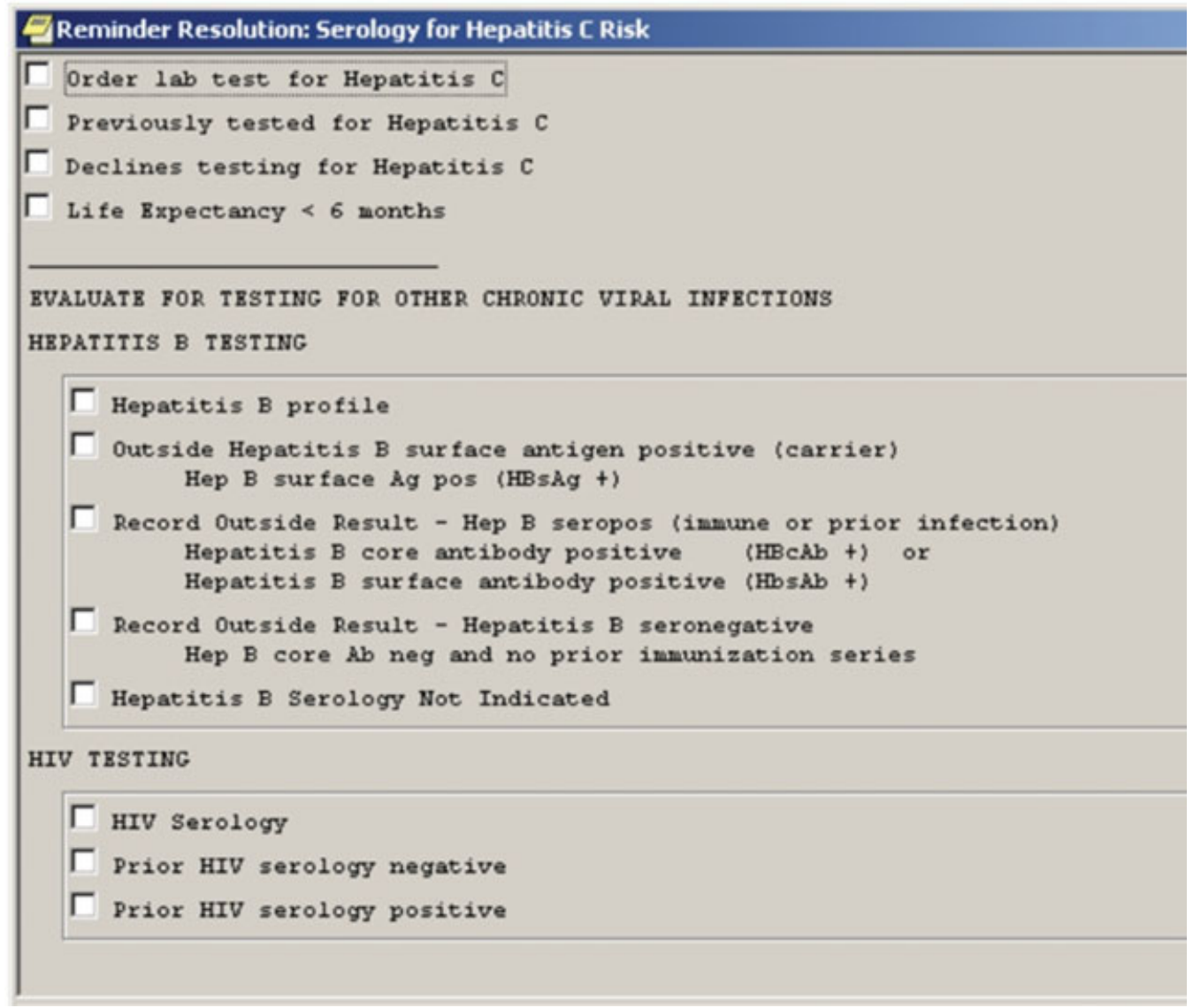

Fig. 2 Example of typical clinical reminder.

7. Links to resources on how to titrate are provided.

8. The provider can make an order for $\beta$-blockers from the clinical reminder.

9. The provider can also request a clinical pharmacy referral.

\section{Usability Review}

\section{Usability Review Methods}

We showed the prototype to key informants at the three sites, and asked them to walk through the reminder as if they were seeing it for a patient. Their feedback was used to further refine the prototype. The revised version was subsequently evaluated via a small pilot usability test, involving a scenario-based walk-through assessment done remotely from the participating sites. The PCPs were given mock-ups of the prototype showing data and providing relevant clinical notes for real patients (anonymized records that were used with proper approval). These mock-ups were Portable Document Format files with internal linking but no other functionality. There were two scenarios, both involving older patients with suppressed ejection fraction HF and comorbidities including COPD, who were recently discharged after being in the hospital due to HF exacerbation. One was a true positive in which the patient qualified for guideline-recommended levels of $\beta$-blocker but was not receiving it. The other scenario was a false positive in which the patient did not qualify because of blood pressure issues. Information was elicited via think-aloud and probe questions.

Further evaluations have been done (see Refs. 54 and ${ }^{55}$ ). However, the clinical reminder has not yet been implemented.

\section{Results of Usability Review}

Three key informants (1 PharmD, 2 MD PCPs) participated in the informal usability review of the initial prototype. They expressed positive opinions about the general design approach. They also provided feedback about specific functional and layout issues. These recommendations were implemented in the revised prototype ( - Fig. 2).

Three PCPs (1 NP, 2 MDs) participated in the scenariobased pilot usability test. These participants were able to make sense of the clinical reminder and use it to make decisions about $\beta$-blocker titration for systolic HF patients with depressed ejection fraction. The PCPs noted the utility of providing the list of approved drugs and target doses, and the recent history of weight, blood pressure, and heart rate.

\section{Discussion}

In this article, we describe a process for using implementation and sociotechnical frameworks as part of a CTA-based requirements development process for a clinical reminder concerning 


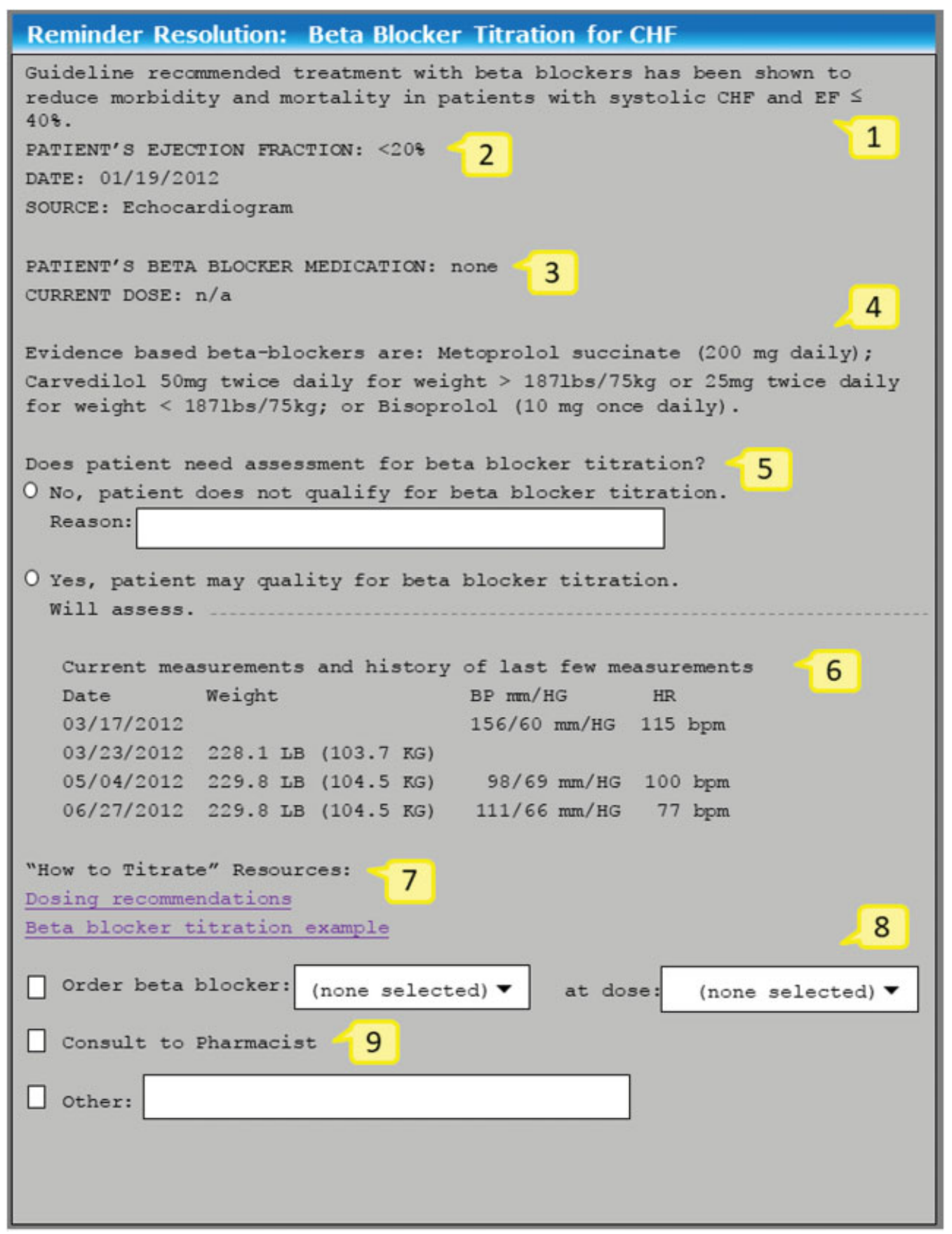

Fig. 3 Prototype used in usability pilot test.

underuse of appropriate $\beta$-blocker medications for $\mathrm{HF}$ patients with depressed ejection fraction. Our design includes several functions that help support the needs of the providers and facilitates adoption. Unlike prior HF CDSSs, ${ }^{18,19}$ this one is a clinical reminder that appears without any action by the provider. However, it only appears when the text extraction software has identified the patient as lacking guidelinerecommended $\beta$-blocker treatment despite having reduced ejection fraction. This design is congruent with recommendations to support both automatic well-learned cognitive processing while at the same time providing tools to attend to the issue if needed. Combining both automatic and deliberative processing has been recommended as an approach to CDSS design. ${ }^{40}$ The clinical reminder presents the evidence-based rational for the treatment with $\beta$-blocker which activates practice values. When providers are familiarized with the evidence, it can lead to better attentiveness to the clinical reminder. ${ }^{56}$ It facilitates the execution of rapid, well-learned habits among providers who have sufficient experience in deciding upon and initiating $\beta$-blocker titration, thereby supporting automatic, pattern-matching cognitive processing. At the same time, it supports providers who still require slower, more explicit processing to make the decision and start the titration process. ${ }^{40,56}$ In this way, it supports the integration of 
these different cognitive processes. Additionally, there is an open text field for providers to describe reasons why $\beta$-blocker titration may not be applicable to their patient. This avoids constraining the provider's options, and it captures data that can be used by system administrators to refine the algorithm to reduce false positives. Considering these design features, and the results of the initial evaluation, we believe our clinical reminder prototype addresses the usability and integration problems that have caused problems with other clinical reminders. ${ }^{57}$

Many of the strengths of the design are due to our innovative requirements elicitation approach, using CTA enhanced with the PARIHS, HIT sociotechnical, and Cabana frameworks. Had we followed the same clinical reminder format used for simpler decisions, the design would have only had a statement that the patient was not getting the right $\beta$-blocker type and/or dose, and checkbox options to either initiate titration or indicate that the patient does not qualify for $\beta$-blocker titration.

Had we done a CTA but without integration of the PARIHS, HIT sociotechnical, and Cabana frameworks, the design would likely have still included some clinical data and treatment guideline information, but most likely not many other design features. These are presented in -Table 3 .

The decision to present the ejection fraction and the recent measurements of weight, blood pressure, and heart rate was based on both the role of that information in the provider's cognitive work, but also on the HIT sociotechnical issue of how long it takes providers to access that information by themselves in the EHR.

Increasing the use of $\beta$-blockers in qualifying patients is a difficult endeavor, and will require more than a clinical reminder, however sophisticated it may be. Nonetheless, this clinical reminder addresses many barriers to guideline adherence, and shows promise for improving treatment decisions. It can make providers more familiar with and knowledgeable about the guidelines and the benefit to their

Table 3 Design features resulting from application of frameworks

\begin{tabular}{|l|l|}
\hline Design feature & Frameworks \\
\hline The rationale for guideline & $\begin{array}{l}\text { PARIHS } \\
\text { Cabana (attitude) }\end{array}$ \\
\hline $\begin{array}{l}\text { The organization to allow quick } \\
\text { resolution for false positives, and } \\
\text { for providers who are very familiar } \\
\text { with deciding upon and initiating } \\
\beta \text {-blocker titration }\end{array}$ & $\begin{array}{l}\text { HIT sociotechnical } \\
\text { (time pressures) } \\
\text { Cabana (practice) } \\
\text { PARIHS (facilitation) }\end{array}$ \\
\hline $\begin{array}{l}\text { The upfront presentation } \\
\text { of } \beta \text {-blocker doses }\end{array}$ & Cabana (knowledge) \\
\hline $\begin{array}{l}\text { The links to resources } \\
\text { on how to titrate }\end{array}$ & $\begin{array}{l}\text { Cabana (knowledge) } \\
\text { PARIHS (facilitation) }\end{array}$ \\
\hline $\begin{array}{l}\text { The option for consult } \\
\text { to pharmacist }\end{array}$ & $\begin{array}{l}\text { HIT sociotechnical } \\
\text { (workflow) } \\
\text { PARIHS (facilitation) }\end{array}$ \\
\hline
\end{tabular}

Abbreviations: HIT, health information technology; PARIHS, Promoting Action on Research Implementation in Health Services. patients. It supports them in developing skill and comfort with titration. It facilitates better utilization of clinical pharmacy.

This clinical reminder integrates a great deal of clinical data and treatment guideline information compared with typical clinical reminders. In that sense, it supports the creation of an accurate "situation model." ${ }^{58}$ This is important, given the complexity of the decision and treatment being addressed. Typical reminders target screening activities. Few if any other clinical reminders in the VA or other health care systems involve consideration of this level of clinical data, nor pharmacological interventions of this complexity.

In these respects, this study is helping to explore the use of clinical reminders and other CDSS tools for more complicated decision processes, and involving the integration of more sophisticated algorithms (e.g., those using free text analysis). Furthermore, this is being done in the relatively distributed context of primary care.

These challenges call for more proactive development methods. Our study shows the feasibility and value of using CTA-based requirements elicitation to incorporate implementation and adherence frameworks early on in the development process.

\section{Limitations}

\section{Limitations of the Clinical Reminder Design}

One limitation of our design is inherent with the clinical reminder function. The provider must access that patient's record. If a provider does not have an appointment with that patient or other reason to look in that record, the patient's treatment will not be evaluated. A future tool we are planning is a periodic report providing information on qualifying patients at risk, which can be integrated with panel management tools.

One compromise in the design is the amount of clinical data it shows. There are a very large number of potentially relevant factors for a clinician to consider for the decision to initiate $\beta$-blocker titration. We could fit only a small number in the design without overwhelming the use. We prioritized those data that would facilitate quick decisions whether to exclude or continue evaluating. For many cases, providers will need to look into the patient's record.

The announced change in the VHA's EHR to a new platform ${ }^{59}$ presents a limitation in terms of the longevity of the specific design solution. However, clinical reminder functions are common across all major EHR platforms. ${ }^{60}$ The results of this study will inform the design of a new $\beta$-blocker treatment reminder for the new platform, as well as for platforms used by other health care systems. Furthermore, the broader findings of this study (that requirements development can be aided though the use of CTA-type requirements elicitation enhanced via implementation and sociotechnical frameworks) not only remain relevant, but also are arguably more important now given the requirements development that must take place as part of customization and configuration of the new platform. 


\section{Limitations of the Study}

Our CTA relied only on interviews. We were unable to conduct observations of providers working on HF treatment issues. We had providers go through case simulations, but only as part of the preliminary evaluation of the prototype.

Another limitation is that our CTA was conducted to inform the design of the CDSS. It was not designed to explore the full complexity of teamwork in the context of chronic disease management. Additionally, our sample of PCPs for the CTA interviews included only two physicians (the rest were nurse practitioners), potentially underrepresenting physicians' views.

The tool has not been implemented yet, so we do not have any data on the impact to guideline adherence or impact to patients care or resulting impact to health.

\section{Conclusion}

We have developed a decision support tool to address the lack of guideline adherent $\beta$-blocker treatment for $\mathrm{HF}$ patients with depressed ejection fraction. To address the challenges with implementation of assessment for and initiation of titration, we conducted a CTA-based requirements elicitation process that incorporated three relevant frameworks (PARIHS, HIT sociotechnical, and Cabana). The incorporation of these frameworks contributed to design features that should facilitate providers' decision making, resource use, and treatment execution.

\section{Clinical Relevance Statement}

Our work explores how clinical reminders could be used to help increase the rate of qualifying heart failure patients (with depressed ejection fraction) who receive titration to optimal doses of appropriate $\beta$-blockers. Our work also describes methods that should reduce the risk of developing an HIT tool that does not fit into the organization. Incorporating PARIHS, HIT socio-technical frameworks, or similar into the requirements elicitation and development process can help identify needs regarding implementation and integration into the larger sociotechnical system.

\section{Multiple Choice Question}

According to our study, one way to ensure a CDSS design incorporates factors related to guideline adherence and implementation is to:

a. Include questions relevant to adherence and implementation in the requirements elicitation phase.

b. Follow the design of previous CDSS tools that are in use.

c. Include mechanisms for penalizing providers who fail to follow the guidelines.

d. Make sure it is presented constantly to providers, with no way to quickly dismiss it, to help embed it in memory.

Correct Answer: The correct answer is option a, "Include questions relevant to adherence and implementation in the requirements elicitation and development phase." Includ- ing such questions in the requirements elicitation and development phase will help make sure that the design addresses the needs related to why providers may not be following the guidelines, and why providers may not use the CDSS tool. Answer B ("Follow the design of previous CDSS tools that are in use") may not result in a design that works for the specific clinical decision at hand. Answers C and D are ways that may not actually help with adoption of the tool or adherence to the guideline, and will likely have serious negative impact on providers' performance and morale.

Protection of Human and Animal Subjects

This study was approved by the Baylor College of Medicine Institutional Review Board.

\section{Funding}

This study was supported by the U.S. Department of Veterans Affairs, Veterans Health Administration, Health Services Research and Development Service (CRE 12-037). The views expressed are those of the authors and not those of the Department of Veterans Affairs or affiliated institutions.

\section{Conflicts of Interest}

None.

\section{Acknowledgment}

We thank the participants and the leadership of the VA VISN and participating facilities.

\section{References}

1 Fang J, Mensah GA, Croft JB, Keenan NL. Heart failure-related hospitalization in the U.S., 1979 to 2004. J Am Coll Cardiol 2008; 52(06):428-434

2 Yancy CW, Jessup M, Bozkurt B, et al; WRITING COMMITTEE MEMBERS; American College of Cardiology Foundation/American Heart Association Task Force on Practice Guidelines. 2013 ACCF/ AHA guideline for the management of heart failure: a report of the American College of Cardiology Foundation/American Heart Association Task Force on practice guidelines. Circulation 2013; 128(16):e240-e327

3 Yancy CW, Jessup M, Bozkurt B, et al. 2017 ACC/AHA/HFSA focused update of the 2013 ACCF/AHA guideline for the management of heart failure: a report of the American College of Cardiology/American Heart Association Task Force on Clinical Practice Guidelines and the Heart Failure Society of America. J Am Coll Cardiol 2017;70(06):776-803

4 Lloyd-Jones D, Adams R, Carnethon M, et al; American Heart Association Statistics Committee and Stroke Statistics Subcommittee. Heart disease and stroke statistics-2009 update: a report from the American Heart Association Statistics Committee and Stroke Statistics Subcommittee. Circulation 2009;119(03):e21-e181

5 Roger VL, Go AS, Lloyd-Jones DM, et al; American Heart Association Statistics Committee and Stroke Statistics Subcommittee. Heart disease and stroke statistics-2011 update: a report from the American Heart Association. Circulation 2011;123(04):e18-e209

6 Hunt SA, Abraham WT, Chin MH, et al. 2009 focused update incorporated into the ACC/AHA 2005 Guidelines for the Diagnosis and Management of Heart Failure in Adults: a report of the American College of Cardiology Foundation/American Heart Association Task Force on Practice Guidelines: developed in collaboration with the International Society for Heart and Lung Transplantation. Circulation 2009;119(14):e391-e479 
7 Patel P, White DL, Deswal A. Translation of clinical trial results into practice: temporal patterns of $\beta$-blocker utilization for heart failure at hospital discharge and during ambulatory follow-up. Am Heart J 2007;153(04):515-522

8 Metra M, Torp-Pedersen C, Cleland JGF, et al; COMET investigators. Should beta-blocker therapy be reduced or withdrawn after an episode of decompensated heart failure? Results from COMET. Eur J Heart Fail 2007;9(09):901-909

9 Packer M, Bristow MR, Cohn JN, et al; U.S. Carvedilol Heart Failure Study Group. The effect of carvedilol on morbidity and mortality in patients with chronic heart failure. N Engl J Med 1996;334(21): 1349-1355

10 Krum H, Sackner-Bernstein JD, Goldsmith RL, et al. Double-blind, placebo-controlled study of the long-term efficacy of carvedilol in patients with severe chronic heart failure. Circulation 1995;92 (06):1499-1506

11 Metra M, Nardi M, Giubbini R, Dei Cas L. Effects of short- and longterm carvedilol administration on rest and exercise hemodynamic variables, exercise capacity and clinical conditions in patients with idiopathic dilated cardiomyopathy. J Am Coll Cardiol 1994;24(07):1678-1687

12 Fisher ML, Gottlieb SS, Plotnick GD, et al. Beneficial effects of metoprolol in heart failure associated with coronary artery disease: a randomized trial. J Am Coll Cardiol 1994;23(04):943-950

13 The Cardiac Insufficiency Bisoprolol Study (CIBIS). CIBIS Investigators and Committees. A randomized trial of beta-blockade in heart failure. Circulation 1994;90(04):1765-1773

14 Adams KF Jr, Fonarow GC, Emerman CL, et al; ADHERE Scientific Advisory Committee and Investigators. Characteristics and outcomes of patients hospitalized for heart failure in the United States: rationale, design, and preliminary observations from the first 100,000 cases in the Acute Decompensated Heart Failure National Registry (ADHERE). Am Heart J 2005;149(02):209-216

15 Fonarow GC, Abraham WT, Albert NM, et al; OPTIMIZE-HF Investigators and Hospitals. Factors identified as precipitating hospital admissions for heart failure and clinical outcomes: findings from OPTIMIZE-HF. Arch Intern Med 2008;168(08): $847-854$

16 Swedberg K, Cleland J, Dargie H, et al. Task Force for the Diagnosis and Treatment of Chronic Heart Failure of the European Society of Cardiology. Guidelines for the diagnosis and treatment of chronic heart failure: executive summary (update 2005): the Task Force for the Diagnosis and Treatment of Chronic Heart Failure of the European Society of Cardiology. Eur Heart J 2005;26(11): 1115-1140

17 Komajda M, Anker SD, Cowie MR, et al; QUALIFY Investigators. Physicians' adherence to guideline-recommended medications in heart failure with reduced ejection fraction: data from the QUALIFY global survey. Eur J Heart Fail 2016;18(05):514-522

18 Leslie SJ, Hartswood M, Meurig C, et al. Clinical decision support software for management of chronic heart failure: development and evaluation. Comput Biol Med 2006;36(05):495-506

19 Toth-Pal E, Wårdh I, Strender L-E, Nilsson G. A guideline-based computerised decision support system (CDSS) to influence general practitioners management of chronic heart failure. Inform Prim Care 2008;16(01):29-39

20 de Vries AE, van der Wal MH, Nieuwenhuis MM, et al. Perceived barriers of heart failure nurses and cardiologists in using clinical decision support systems in the treatment of heart failure patients. BMC Med Inform Decis Mak 2013;13:54

21 Smeets M, Van Roy S, Aertgeerts B, Vermandere M, Vaes B. Improving care for heart failure patients in primary care, GPs' perceptions: a qualitative evidence synthesis. BMJ Open 2016;6 (11):e013459

22 Garvin JH, DuVall SL, South BR, et al. Automated extraction of ejection fraction for quality measurement using regular expressions in Unstructured Information Management Architecture (UIMA) for heart failure. J Am Med Inform Assoc 2012;19(05): 859-866
23 Garvin JH, Elkin PL, Shen S, et al. Automated quality measurement in Department of the Veterans Affairs discharge instructions for patients with congestive heart failure. J Healthc Qual 2013;35(04):16-24

24 Ansari M, Shlipak MG, Heidenreich PA, et al. Improving guideline adherence: a randomized trial evaluating strategies to increase $\beta$ blocker use in heart failure. Circulation 2003;107(22):2799-2804

25 Gheorghiade M, Colucci WS, Swedberg K. $\beta$-blockers in chronic heart failure. Circulation 2003;107(12):1570-1575

26 Østbye T, Yarnall KS, Krause KM, Pollak KI, Gradison M, Michener $\mathrm{JL}$. Is there time for management of patients with chronic diseases in primary care? Ann Fam Med 2005;3(03):209-214

27 Bodenheimer T, Chen E, Bennett HD. Confronting the growing burden of chronic disease: can the U.S. health care workforce do the job? Health Aff (Millwood) 2009;28(01):64-74

28 Fuat A, Hungin APS, Murphy JJ. Barriers to accurate diagnosis and effective management of heart failure in primary care: qualitative study. BMJ 2003;326(7382):196

29 Gurses AP, Marsteller JA, Ozok AA, Xiao Y, Owens S, Pronovost PJ. Using an interdisciplinary approach to identify factors that affect clinicians' compliance with evidence-based guidelines. Crit Care Med 2010;38(8, Suppl):S282-S291

30 Rycroft-Malone J. The PARIHS framework-a framework for guiding the implementation of evidence-based practice. J Nurs Care Qual 2004;19(04):297-304

31 Sittig DF, Singh H. A new sociotechnical model for studying health information technology in complex adaptive healthcare systems. Qual Saf Health Care 2010;19(Suppl 3):i68-i74

32 Carayon P, Schoofs Hundt A, Karsh B-T, et al. Work system design for patient safety: the SEIPS model. Qual Saf Health Care 2006;15 (Suppl 1):i50-i58

33 Holden RJ, Carayon P, Gurses AP, et al. SEIPS 2.0: a human factors framework for studying and improving the work of healthcare professionals and patients. Ergonomics 2013;56(11):1669-1686

34 Cabana MD, Rand CS, Powe NR, et al. Why don't physicians follow clinical practice guidelines? A framework for improvement. JAMA 1999;282(15):1458-1465

35 Lau R, Stevenson F, Ong BN, et al. Achieving change in primary care-causes of the evidence to practice gap: systematic reviews of reviews. Implement Sci 2016;11:40

36 Sheehan B, Nigrovic LE, Dayan PS, et al; Pediatric Emergency Care Applied Research Network (PECARN). Informing the design of clinical decision support services for evaluation of children with minor blunt head trauma in the emergency department: a sociotechnical analysis. J Biomed Inform 2013;46(05):905-913

37 Crandall B, Klein GA, Hoffman RR. Working Minds: A Practitioner's Guide to Cognitive Task Analysis. Cambridge, MA: MIT Press; 2006:332

38 Militello LG, Dominguez CO, Lintern G, Klein G. The role of cognitive systems engineering in the systems engineering design process. Syst Eng 2009;13(03):261-273

39 Patel VL, Kannampallil TG. Human factors and health information technology: current challenges and future directions. Yearb Med Inform 2014;9(01):58-66

40 Weir CR, Rubin MA, Nebeker J, Samore M. Modeling the mind: how do we design effective decision-support? J Biomed Inform 2017;71S(Supplement):S1-S5

41 Bisantz A, Roth E. Analysis of cognitive work. Rev Hum Factors Ergon 2007;3:1-43

42 Militello LG, Hutton RJ. Applied cognitive task analysis (ACTA): a practitioner's toolkit for understanding cognitive task demands. Ergonomics 1998;41(11):1618-1641

43 Potter S, Roth EM, Woods DD, Elm WC. Bootstrapping multiple converging cognitive task analysis techniques for system design. In: Schraagen JM, Chipman SF, Shalin VL, eds. Cognitive Task Analysis. Mahwah, New Jersey: Lawrence Erlbaum Associates; 2000:317-340

44 Rosland A-M, Nelson K, Sun H, et al. The patient-centered medical home in the Veterans Health Administration. Am J Manag Care 2013;19(07):e263-e272 
45 Steinman MA, Harlow JB, Massie BM, Kaboli PJ, Fung KZ, Heidenreich PA. Age and receipt of guideline-recommended medications for heart failure: a nationwide study of veterans. J Gen Intern Med 2011;26(10):1152-1159

46 Klein GA, Calderwood R, MacGregor D, Inc KA, Springs Y. Critical decision method for eliciting knowledge. Syst Man Cybern IEEE Trans On. 1989;19(03):462-472

47 Ritchie J, Spencer L. Qualitative data analysis for applied policy research. In: Bryman A, Burgess B, eds. Analyzing Qualitative Data. New York: Routledge; 2002:173-194

48 Gale NK, Heath G, Cameron E, Rashid S, Redwood S. Using the framework method for the analysis of qualitative data in multidisciplinary health research. BMC Med Res Methodol 2013;13 (01):117

49 Xiao Y, Parker SH, Manser T. Teamwork and collaboration. Rev Hum Factors Ergon 2013;8(01):55-102

50 Rodriguez HP, Giannitrapani KF, Stockdale S, Hamilton AB, Yano EM, Rubenstein LV. Teamlet structure and early experiences of medical home implementation for veterans. J Gen Intern Med 2014;29(02, Suppl 2):S623-S631

51 True G, Stewart GL, Lampman M, Pelak M, Solimeo SL. Teamwork and delegation in medical homes: primary care staff perspectives in the Veterans Health Administration. J Gen Intern Med 2014;29 (Suppl 2):S632-S639

52 Lipshitz R. Rigor and relevance in NDM: how to study decision making rigorously with small $\mathrm{Ns}$ and without controls and (inferential) statistics. J Cogn Eng Decis Mak 2010;4(02):99-112

53 Clinical Reminders Manager's Manual PXRM*2.0*53. Product Development, Office of Information and Technology, Department of Veterans Affairs; 2015. Available at: https://www.va.gov/vdl/
documents/Clinical/CPRS-Clinical_Reminders/pxrm_2_mm.doc. Accessed October 20, 2017

54 Benally P, Smith MW, Brown C, et al. Barriers to Automating Beta Blocker Titration in Heart Failure at the Point of Care. Poster session presented at: AMIA 2017 Annual Symposium; 2017 November 4-8; Washington, DC; 2017

55 Yazzie V, Smith M, Brown C, et al. The use of informatic tools to improve $\mathrm{CHF}$ patients within the VA health care system. Association of American Indian Physicians 46th Annual Meeting, Shawnee, OK, July 29, 2017

56 Weir C, Brunker C, Butler J, Supiano MA. Making cognitive decision support work: Facilitating adoption, knowledge and behavior change through QI. J Biomed Inform 2017;71S(Supplement):S32-S38

57 Saleem JJ, Patterson ES, Militello L, Render ML, Orshansky G, Asch SM. Exploring barriers and facilitators to the use of computerized clinical reminders. J Am Med Inform Assoc 2005;12(04):438-447

58 Wyer RS Jr. Social Comprehension and Judgment: The Role of Situation Models, Narratives, and Implicit Theories. 1st ed. New York, NY: Psychology Press; 2004:440

59 U.S. Department of Veterans Affairs. VA Secretary announces decision on next-generation Electronic Health Record. Available at: https://www.va.gov/opa/pressrel/pressrelease.cfm?id=2914. Accessed October 19, 2017

60 Wright A, Sittig DF, Ash JS, et al. Development and evaluation of a comprehensive clinical decision support taxonomy: comparison of front-end tools in commercial and internally developed electronic health record systems. J Am Med Inform Assoc 2011;18 (03):232-242 